\title{
Dealing with Environment: Indigenous Environmental Ethics, Ethiopia
}

\author{
Tadie Degie Yigzaw \\ Department of Civics and Ethical Studies, Dilla University, Dilla, Ethiopia
}

Email address:

degietadie@gmail.com

\section{To cite this article:}

Tadie Degie Yigzaw. Dealing with Environment: Indigenous Environmental Ethics, Ethiopia. International Journal of Philosophy. Vol. 5, No. 4, 2017, pp. 36-43. doi: 10.11648/j.ijp.20170504.11

Received: June 21, 2017; Accepted: July 11, 2017; Published: September 29, 2017

\begin{abstract}
The purpose of this study is to scrutinize the indigenous environmental ethics of the Gedeo people, in Gedeo zone focusing on sage and elite informants on three randomly selected woredas (the administrative unit in Ethiopia which is above kebele and below zone). It is assumed that the views of both sage and elite informants represents the indigenous environmental ethics of the Gedeo people is holistic and implicit. Methodologically, qualitative research approach has been employed. Theoretically, the meaning, nature, significance and the roles of environmental ethics were discussed with the informants and a nexus has been sought vis-à-vis scholarly perspectives. Besides, the moral relations between the Gedeo people with their environment were discussed. Despite the divergent meanings given by informants, the meaning of indigenous environmental ethics for the Gedeo people, undoubtedly, is understandable implicitly and found in unwritten form in their cultural practices, institutions, religious systems, history, and oral traditions. It is also holistic in its nature since it encompasses both anthropocentric (weak) and non-anthropocentric views. Besides, they provide utilitarian and non-utilitarian, intrinsic and extrinsic values and both the power of domination and stewardship for humankind towards the environment. Morality, religion, culture, history, indigenous knowledge, social institutions are the Archimedean points of environmental obligation. Generally, for the Gedeo people the issue of justice, integrity, and stability is not merely human virtues but they also extend them to the environment as well.
\end{abstract}

Keywords: Indigenous, Indigenous People, Environment, Ethics, Indigenous Environmental Ethics, Environmental Ethics

\section{Introduction}

In this study the researcher is focused on indigenous environmental ethics of the Gedeo people. To do this research rewardingly having a general thought about what the term indigenous people connotes and the meanings of environmental ethics is so relevant since having an impression about the general thought is logically pertinent to recognize a particular thought.

Besides, there is no common consensus in defining the term indigenous people However, for Sillitoe (1998) the common features are include self- identification at the individual level and accepted by the community as their member; historical continuity with pre-colonial and/or presettler societies; strong link to territories and surrounding natural resources; distinct social, economic or political systems; distinct language, culture and beliefs; for monodominant groups of society; and resolve to maintain and reproduce their ancestral environments and systems as distinctive peoples and communities.

According to Hayden (1994), there are numerous and different indigenous environmental ethics in all over the world which is not yet explored. Indigenous environmental ethics, each adopted to its cultural and ecological bioregion. So developing a network of indigenous environmental ethics helps us to march towards the goal. But we shall need some common environmental attitudes and values on which to base a common vision of a whole and healthy world. There are a plurality of environmental attitudes and values drawn from a multiplicity of independent intellectual traditions.

Sillitoe (1998) affirms that indigenous peoples take the largest share of the world's cultural diversity. Their distinct ways of life vary considerably from one location to another. Of the estimated 6,000 cultures in the world, about 5,000 are indigenous. Approximately three-quarters of the world's 6,000 languages are spoken by indigenous peoples. The 
United Nations Conference on Environment and Development, held in Rio de Janeiro, Brazil, in June 1992, was an imperative development for indigenous peoples and their rights related to the environment. The Conference, or Earth Summit as it is called, recognized that indigenous peoples and their communities have a critical role to play in managing and developing the environment. The value of indigenous peoples' traditional knowledge and practices was acknowledged, and the international community committed itself to promoting, strengthening and protecting the rights, knowledge and practices of indigenous peoples and their communities. So, it is estimated that there are more than 370 million indigenous people spread across 70 countries worldwide. Practicing unique traditions, they retain social, cultural, economic and political characteristics that are distinct from those of the dominant societies in which they live.

Historically, the philosophy of nature is as old as pre Socratic traditions (pre-Socratic philosophers). Pre-Socratic philosophers were considered as "natural philosophers" since environment is the origin of their philosophical wonder and speculation. That is the rationality of relating the history of environmental ethics with the pre-Socratic traditions. Pythagoreans have given due attention to the environment since they argued that "all is god, and the world is god". This implies, they provided intrinsic value and moral standings to the environment. Aristotle, a classical Greek philosopher, promotes environmental ethics hence he said that "in all natural things there is something wonderful" (Hayden, 1994, p. 46).

Besides, Botzler (1998) insists that tracing back to the preSocratic traditions different philosophers initiated the thoughts of environmental ethics during the classical (antiquity), medieval, modern and contemporary periods; in the medieval period Saint Francis of Assisi who wasa catholic priest in Italy known as the patron Saint of animals; laid solid foundation for environmental ethics. For Saint Francis man should respect the creation of God and make animals friendly because they are created by God. In the modern era the thoughts of environmental ethics also attracts the attention of different thinkers. According to Jeremy Bentham and John Stuart Mill sentience animals should have moral standing since they feel pleasure and suffer pain.

The scholastic debate between thinkers like Aldo Leopold, Lynn White, Arae Neass, Christopher Stone, J. Baird Callicott, Holmes Rolston, Paul Taylor, and other philosophers have led to the development of different theories of environmental ethics such as eco-centrism, biocentrism, anthropocentrism, deep-ecology and eco-feminism (VanDeVeer and Pierce, 1994, pp. 211-250). These theories provide different justification about the meaning, concept, nature and role of environmental ethics in addressing global environmental crisis. Although different environmental ethicists provide different meaning about environmental ethics but the working thought are the moral relationships between human beings with the environment. As perLynn White (1967) in his published article "The Ecological Roots of Environmental Crisis" the main stance of Judeo- Christian thinking contributed to the exploitation of nature because human beings have occupied privileged positions over nature. Human beings are given by God the authority to exploit nature as they wish, since human beings are created in the image and likeness of God. So they conquer nature and this world view is responsible for environmental crisis. For White fundamental shifts in culture, attitude is required to avoid environmental crisis. While for Aldo Leopold's in his article "A Sand County Almanac" he argued that "A thing is right when it tends to preserve the integrity, stability, and beauty of the biotic community. It is wrong when it tends otherwise" is Leopold's criterion of right/wrong (Callicott, 1987, pp. 173).

Following this different argumentation, for Hayden (1994), in the 1970s environmental ethics emerged as a new discipline since there were industrial revolution, "population bomb", and environmental crisis. As a result, philosophers entered this debate concerned citizens. There are discussions on ethical issues that are relevant to practical issues. The skill they acquired in universities helps them to address different problems. Therefore, different people in the world have their own unique environmental ethics since it is related with the values of the society.

In view of that, at the international level for the first time different religious leaders also showed their commitment towards the environment. For instance, Hayden (1994) explains this idea; in 1987 representatives of Christianity, Judaism, Islam, Buddhism and Hinduism met in Assisi, Italy (the birth place of St. Frances to declare their religious commitment to preserving the planet.

\section{Material and Methods}

\section{Research Method}

The approach followed in this research is qualitative in nature since the main objective of this research is scrutinizing the indigenous environmental ethics of the Gedeo people within a special emphasis of the meaning, notion, nature, and its role within the socio-economic relations of the people. Therefore, to conduct an in-depth study in this area qualitative approach is more pertinent for this study since qualitative methodology enables in-depth investigation of a specific phenomena in particular environment such as groups of people, institutions, cases, and geographical areas. Also, this approach lets to gather detailed data on perceptions, socio-cultural phenomena, behaviors and the reasons that govern such behaviors (Kothari, 2004, pp. 15-18).

\subsection{Sample and Sampling Techniques}

As the, the researcher affirm that the central area of the research is the Gedeo zone; these people reside in Gedeo zone and this zone contains of six different woredas. Thus it is a relatively large community. For the purpose of this research three woredas (Dilla zuriya, wonago, and Yirgacheffe) are randomly selected because of the homogenous nature of the people. For each woredas the focus of the researchers focused on community sages and selected educated informants (elites) in order to gather 
credible information. These different segments of the community (respondents) are purposively incorporated and interviewed; since this enables to triangulate and to know the indigenous environmental ethics of the Gedeo people. The sage informants were made a focus group discussion in the three selected woredas ( 8 members in each FGD) and two educated informants in each woreda were interviewed. My informants have different religions, social backgrounds, age levels and include both sexes. Therefore, a total of 30 informants were participated in both the interview and focus group discussion.

\subsection{Data Source and Data Collection Tools}

To make this research credible both primary and secondary data sources were used. Both primary and secondary data sources were enriched through primary and secondary data collection methods. The primary data were collected through an interview, observation and focus group discussions. While, the secondary data were collected through document analysis from different sources like books, journal articles, and documents which have a direct relevance with the research.

\subsubsection{Interview}

The interview method of collecting data involves presentation of oral-verbal stimuli and reply in terms of oralverbal responses. This method can be used through personal interviews and, if possible, through telephone interviews (Kothari, 2004, p. 18). However, the researcher is not use telephone interview unless there is be difficulties.

Thoroughly and semi-structured face-to-face interviews are held with key informants since it allows us to swerve and pose divergent questions. Respondent selection techniques were mainly based on purposive sampling in the study areas. Interview is a primary data collection instrument which respondents provide information. The interview is intended to scrutinize the indigenous environmental ethics of the Gedeo people with the key interviewees (Gedeo sages and selected educators).

\subsubsection{Focus Group Discussions}

According to Krueger (1988) a focus group discussion (FGD) is a good way to gather together people from similar backgrounds or experiences to discuss a specific topic of interest. The group of participants is guided by a moderator (or group facilitator) who introduces topics for discussion and helps the group to participate in a lively and natural discussion amongst themselves.

Therefore, the researcher is preparing questions of focus group discussion that are conducted purposely selected respondents of the Gedeo people from three different woredas. Respondents are organized into different groups based on their similarity in status, profession, age, gender and other attributes to conduct the focus group discussion effectively. Thus, the researchers used focus group discussion to investigate indigenous environmental ethics and its role in socio-economic aspects.

\subsubsection{Observation}

It is a social research technique that involves the direct observation of phenomena in their natural setting. Marshall and Rossman (1989) define observation as "the systematic description of events, behaviors, and artifacts in the social setting chosen for study". Observations enable the researcher to describe existing situations using the five senses. Interviewing, observation, and document analysis, are qualitative methods of data collection.

\subsubsection{Document Analysis}

Document analysis is one of the main means (method) of collecting secondary data in the area of research. Therefore, to explore the indigenous environmental ethics of the Gedeo people this method of data collection is so vital. So, the researcher used different documents within the research area as well as outside the area if there are available documents within the issue at hand.

\subsection{Data Analysis}

The collected data (from primary and secondary sources) are analyzed by using qualitative techniques. As such, the data gathered through interview from sages and leaders are transcribed into themes and analyzed in connection with the existing literatures. After the data have been collected, the researchers turns to the task of analyzing them (Kothari, 2004: 18). The researchers are analyzed, evaluate and synthesize those different views of the respondent through relating within the secondary sources. Thematic categorizations were drawn from the major points raised in the research questions. The data gained from differing sources were finally compared, analyzed, and synthesize with the purpose of critical examination of their various claims about the indigenous environmental ethics of the Gedeo people.

\section{Results and Discussion}

In this section, I have shown how the Gedeo community inspect and understand the meaning, nature, scope, and significance of environmental ethics. Besides, how the Gedeo people morally relate themselves to their environment would be the other indispensable scheme. Likewise, the role of environmental ethics in the socio-economic aspects of the people would be the other imperative part of this section.

Based on the research questions, interviews were conducted and focus group discussions were held. In addition to this, field observation and document analysis were also employed. Both focus group discussions and interviews were conducted in three selected woredas. The focus groups in the three woredas were set to have 8 members, each. And two educated informants in each of the three woredas were interviewed. Accordingly, a total of 30 informants were consulted.

\subsection{The Meaning, Nature and Significance of Environmental Ethics for the Gedeo People}

Different environmental ethicists provide different 
meaning about environmental ethics. But the working thoughts are the moral relationships between human beings with the rest of nature (Andrew Light et al, 2003, p. 8). The researchers, intended to show the meaning, nature, scope and significance of environmental ethics in the study area. As some sage discussants point out, environmental ethics is the "moral duty that human beings show towards the environment (plants and animals)". Likewise, as per some elite community informants reveal; environmental ethics is "the spontaneous and harmonious relationship between every person with the environment to establish a good and stable future". This implies that the meaning of environmental ethics is understandable in the oral tradition of the people even if it is not supported by literature.

Some sage discussants believed that the relation between man and the environment (plants and animals) is based on the essence of utilitarian and instrumental value. For them their moral relations between plants and animals are obligatory since they are the sources of revenue. The relation is not based on consent rather it is based on law of nature. Therefore, as per the sage discussants, the issue of environmental ethics is "the question of survival; life or death".

As indicated above, environmental ethics for some sage informants is focused on plants and animals and the relation between plants and animals with their community. This connotation is narrow and ignores the abiotic entities of the environment. Nevertheless, for many sage informants, environmental ethics is the moral relation between humankind with the entire environment. Unlike some community sages, the elites of the community understand environmental ethics in a broader way because the meaning and nature of environmental ethics encompasses the broader environment. The understandings of the elites of the community are closer for the academicals understanding of environmental ethics than same sages. This shows there is a little gap in the notion and nature of environmental ethics between the informants.

According to some elite informants, our relation with the environment is so good. That is way the land of the Gedeo is green throughout the year. Both the sages and the elites believe that the merits of environmental ethics are paramount in the life of the community. Some sage informants expressed that a forest is somehow equivalent with an offspring (human). Protecting forest is our moral duty. Our communities have good relation with plants and animals. So forests are like our children. Besides, some informants believed that the environment is related with supernatural power, God since prayer is directly related to the environment in the culture of the community. In times of drought, the community makes a prayer to ask the blessing of God. If after a prayer the rain didn't rain, the people believe that God didn't will the rain. Thus, this view also implies the duty of stewardship to the environment unlike the rights of ownership and domination. Conversely, some informants also argue that human beings have the power of domination over the environment for their day-to-day existence. This view of the informants also supported by the thoughts of Lynn White (1967) who argues that:
God said 'Let us make humankind in our image, according to our likeness; and let them have dominion over the fish of the sea, and over the birds of the air, and over the cattle, and over all the wild animals of the earth, and over every creeping thing that creeps upon the earth. (Genesis 1:26)

According to sage informants "the moral duty of protecting nature is more like a motto for the Gedeo's". The same thought also reflected by the elite informants. For instance, according to some elite informants the ethical responsibility of preserving the environment is the accustomed life of the people since the stable nature of the environment of the community is the testimony of this argument.

As well, as said by sage informants, the relationships between human beings with plants and animals create bad feelings among the people when plants and animals face different challenges. People hurt when big trees are cut down and animals treated badly. For instance, some of our sage informants conveys: The noise that comes out when big trees are cut creates a bad feeling among those who hear this sound. Moreover, they say that let Megeno (God) make you suffer like you made the tree to suffer. Therefore, the Gedeo people morally feel for plants and animals in times of disaster and hardship like that of human beings.

The moral relationship between human beings and animals is also illustrated by elite informants of the community. Peter Singer (1986) in his book "Animal Liberation" discussed about the moral duty of man to protect animals. Because of his concern about animal rights, he is considered as a champion of animal rights. Like Peter Singer, some educated informant argues that animals feel pain and pleasure even though they can't communicate their feelings like human beings. We should use animals properly. For instance, we should use backed animals like donkey according to their ability. We are one parts of the creation of God like animals. God gives a right for us to use animals properly not in an exploitative sense. For instance, if there is negligent handling that will be discouraged. We do not want to attack every part of nature. And we think they have part to play as well. For instance, a hyena will play for it is a scavenger.

Pertaining to the significance of environmental ethics for the Gedeo people, the sage informants believed that "the concern of environmental ethics is not the concern of choice rather it is the issue of survival." Without harmonious relations between the people and the environment life will be difficult since the environment is the source of everything. For instance, the environment is the source of economic sector, social affairs, traditional practices, historical values and cultural elements. The connection between culture and environment is intense among the Gedeo people. The people have spiritual, cultural, social and economic connections with their environment. Traditional laws and practices reflect both an attachment to environment and a responsibility for preserving environment for use by future generations.

Elite informants suggested that the environment have both utilitarian and non-utilitarian values. The Gedeo people protect plants for various reasons. Plants have economic value because they serve as source of food, materials for 
construction, medicine, charcoal, firewood, and forage for livestock and so on. Plants also protect soil erosion, influence climate and provide shade for humans and animals. Thus, in terms of ethics, it is better to say that the preservation of plants is really essential to the Gedeo for a number of utilitarian reasons. Thus, preserving and caring plants and animals is the moral duty of mankind.

Likewise, many informants believed that the moral relations between man and the environment for the Gedeo's are not purely economic reasons and utilitarian justifications. They also have non-utilitarian values. For the Gedeo people plants and animals are aesthetically and spiritually valuable. The Gedeo Community recognizes some plants as sacred trees based on what are essentially spiritual values. These sacred trees in the community are called 'Adbar'. These holy trees are anointed with butter for worshiping activities. Cutting down sacred trees violates the law of Megeno (God). Besides, according to some elite informants, the Gedeo Community provides inherent value for selected few big trees and water bodies since they are means of worshiping and prayer. In their culture building house without planting trees (the shade of plants) is rigorously prohibited because the community believes that the owner of the house will face a bad temper in his entire life. For the Gedeo's there are special plants that are used for the prevention of epidemic disease like Girawa (Mokasa) and Srtie. These trees are untouched and have special considerations. Besides, the Gedeo people relate environmental protection with super natural power. Trees have special value in bringing social justice. For instance, huluqa (It is rainbow shaped wood which used to make social justice. If a person kills another person then he/she must be passed a half circle wood called huluqa before he/she contacts his/her family) is one means of making social justice. For them trees are place of celebration, worshiping, blessing, peace and negotiation.

According to our elite informants the values, beliefs, and practices of the Gedeo push humans to live in harmony with nature. Life in Gedeo is mutually dependent between human beings and the environment. Thus, the environment is an integral part of their day to day existence.

Moreover, I have noticed that most of the Gedeo areas are hilly however; erosion is low because of the utmost forest coverage and high soil fertility management practices. Planting trees which may be useful for the next generation is the tradition of the Gedeo people. For the Gedeo's it is very common to attach trees with the person who has planted it. So, keeping the ecological balance between the present and future generation is the traditional practice for the people. This implies that the indigenous ecological knowledge of the Gedeo is the base for human-environment relations. Therefore, Gedeo's indigenous environmental ethics is implicit, unwritten and found in their cultural practices, social institutions, religious symbols, history and oral traditions.

\subsection{The Moral Relationships of the Gedeo People with Their Environment}

Environmental problems are the result of both human and non-human actions. But environmental problem in anywhere else, is mainly a result of human actions. It is because of the disobedience of the moral obligations of mankind to protect and preserve the environment that environmental crisis has mainly happened now a day. Therefore, the study of the moral relationships between the people with the environment is the primary concern to tackle the problem. Thus, examining the moral relationships of the Gedeo with their environment is imperative.

According to Andrew Light and Holmes Rolston, environmental ethics considers the ethical relationships between people and the natural world and the kind of decisions people have to make about the environment (Holmes Rolston, 2003 , p. 8). Besides, to this connotation of academia, in our discussion with sage informants of the community, all of them assert that every form of exploitation of the environment is morally bad, culturally wrong, and socially ex-communicated. In their views "the culture of the Gedeo binds people to protect nature". As well, religious sentiments, traditional values and practices, force the community to revere the environment. Cultural and religious institutions of the community play its role in protecting the environment. Traditional institutions like the Songo contributed a lot in environmental preservation. They also believe that plants are the sources of traditional medicines, food, firewood, and so on. Therefore, the relationships between plants, animals and human beings are based on utilitarian and non-utilitarian logics. It is morally wrong for the community to contaminate and destroy parts of the environment and to consume a massive share of the earth's natural resources. The communities necessarily rely upon the environment for existence. Because of this reliance we must treat the environments in which we live with due respect - for the sake of current and future human wellbeing. This view of the informants reflects the notion of interdependence of mankind and nature.

Moreover, according to elite informants plants and animals are created for the purpose of serving the interest of human being in the form of economic, cultural, aesthetic and religious values. Man is at the top of the hierarchy and environment is used for human needs. This view of the elites of the community somehow reflects Aristotelian notion of environmental ethics. For Aristotle "nature is hierarchically arranged and plants have the purpose of serving animals and animals have the purpose of serving human beings" (Passmore, 1974, p. 15). Thus, for some elite informants, man has higher value and hegemonic power over nature. This doesn't means that man have an arbitrary power of exploitation. The environment is given for man by Megeno (God) in the sense of stewardship because man is the only rational being on the earth.

On the other hand, some sage informants also argued that the relationships between man and plants and animals are guided by the principles of traditional institutions and religious practices. For them, man is a respected being and has a responsibility to protect the environment and to use it effectively and efficiently. This implies that, man uses the environment for both instrumental and non-instrumental values. 
For the Gedeo's the environment is the sources of economy, aesthetics, culture, and religious practices. The environment actually has a spiritual nature. In the views of sage informants, religion plays a paramount role for environmental protection. For them, "humans have religious obligations to care the environment". Besides, according to same sage informants, "love of nature is love of man". This asserts how people are morally related to each others. Therefore, the relationships between man and nature for the Gedeo, is morally binding, culturally and historically deep rooted. Therefore, for the Gedeo people the issue of justice, integrity, and stability is not merely human virtues but they extend them to the environment as well.

\subsection{The Moral Obligations of the Gedeo People to the Non-human Beings}

\subsubsection{Do the Gedeo's Are in Nature or Truly off Nature?}

In this section, I try to verify and address the questions of do the Gedeo have an obligation to the non-human beings? And are humans are merely in nature or truly off nature?

According to sage informants, the people of the Gedeo have a moral and cultural responsibility to protect and maintain plants and animals. According to some sage informant the protection of the environment emanates from the question of the survival of the man itself. Without plants and animals life on earth is impossible. So the preservation of plants and animals is the issue of either to die or be alive.

Other informants also believe that the people of the Gedeo are one part of nature from the creation of God. This perception of the informants is connected with the thoughts of Aldo Leopold's (1949) "Land Ethics" which says humans should consider themselves as parts of nature and to attempt to maintain "the integrity, beauty, and stability of the biotic community". Besides, the biblical thought also supports the views of the sage informants. The holy bible proves the moral responsibility of man to nature. For instance, Genesis 2 provides an alternate creation story "man is created from the dust and placed in the garden to till and to protect". Besides, in Psalm 104 "human belongs in the same category as other living things on earth". Moreover, elite informants assert that the Gedeo community consider themselves as one component of nature but at the higher stage of the natural environment. Even though the community consider themselves as parts of nature they also believe that man has the power of administrating the natural world in a stable way because man is a rational being unlike other creatures. On the other hand, elite informants believe that traditional institutions, oral traditions, cultural practices and religious institutions preach the moral obligations of man towards nature.

As per the oral tradition of the Gedeo the notion of humanenvironment relations and the moral duty of man towards the environment inherited from the father of the Gedeo's called Deraso. This pioneer father of the community first teaches his successors about the moral duty of protecting the environment. Therefore, for the Gedeo the moral duty of protecting the environment is hierarchically associated and genealogically liked.
In views of the sage informants, the traditional institution of the Gedeo, Songo (It is a traditional institution with a mandate of mediating human-human and humanenvironment interactions in the Gedeo community). Also teaches the moral obligation of man towards the environment. According to sage informants the Songo tell us our duty of protecting plants and animals. Plants and animals are the main sources of our revenue economically. Trees in our community used as a place of our traditional practices and ceremonies. So we do have economical, moral and cultural responsibility of protecting plants and animals.

What's more, the views of both the sage and elite informants about the moral duty of protecting their environment also supported by the teaching of Jesus; which says "man should show concern for animals, birds, and plants (Luke, 13:15, Mattew, 12:11; Attfield, 2001, p. 97). Some informants also said that the Gedeo community plays due attention to the moral status of humans and non-human creatures. For the Gedeo's plants and animals are not merely a property; rather it is intrinsically valuable and requires respect and protection on the parts of its inhabitants. Some discussants also say the present generation is responsible to preserve and maintain natural resources in a good manner to the next generation. This view of the informants is also supported by "The Conservation Ethics" of Gifford Pinchot which advocates the use of natural resources, but utilizing them shrewdly to maximize goodness for the greatest number for a long period of time.

\subsubsection{Do the Gedeo's Have Single Moral Obligation?}

As my finding reveals, the Gedeo society has many moral responsibilities towards the environment. Thus, the Gedeo people believe that the present generation has a moral obligation of transfer a good environment for the coming generation. This obligation is multi-dimensional. The people have moral, religious, cultural and historical duties of preserving and maintain the environment for the next generation. The people believe that destroying the environment is depriving the present and the future generation. So morality, religion, culture, indigenous knowledge, and history are the basis of environmental obligation for the Gedeo people.

\subsection{The Role of Environmental Ethics in the Socio-Economic Aspects of Life of the Community}

In this section, I have shown the role of the indigenous environmental ethics of the Gedeo in their socio-economic aspect of their life. Moreover, I examined in detail the role of indigenous environmental ethics in the social and economical life of the community in particular.

The environment is the source of economy as well as cultural elements. According to our informants, plants and animals are the fundamental elements to the life of the community. They provide wide range of uses to human beings such as medicine, food, shelter, clothing, ritual and religious practices. They believe that the community of the Gedeo conducted animal rearing, bee keeping, cropping systems and 
agro forestry. Trees used as community gathering sites for social affairs; such as Gadaa traditional culture, political and social organizational ceremony and Songo. The later is local court that resolves disagreements on landholding or assesses cases of murder, theft, which helps to know the criminal.

For some informants, like economical values plants also used for social purposes. For instance, in the culture of the Gedeo, Lanxe (it is a kind of plant which is used a marker for making a boarder in the the Gedeo tradition) is used as means of border demarcation. When a boarder is demarcated a young person will always go with the elders. The idea is that the elderly may die in the near future. So the young are like a long living testimony. The young person has the responsibility of knowing this tree. Lanxe is a symbol of justice and fairness. It makes social justice and avoids any forms of boarder conflict. Therefore, plants used in bringing social justice and avoiding boarder disputes. Moreover, this notion also implies how the people of the community are closely related to the environment and the roles of plants in their social life.

Besides, according to elite informants, environmental attitudes and moral views of the community have direct relations with the socio-economic conditions of the community. Since harmonious and ethical relations of the people with the environment have negative or positive impacts on the social and economical conditions of the people. Other informants also said that the agro forestry system of the community is the result of the optimistic moral views of the people towards nature and the harmonious relation between nature and nurture.

Therefore, planting trees for the Gedeo have various functions. Big trees are considered to be sacred and trees are sources of social, cultural, historical and economical values. The Gedeo consider forests as sources of utilitarian and nonutilitarian values. Environment is not merely a property to be exploited by the humans without care and respect. It is intrinsically valuable and requires respect and care by its inhabitants. The people understand the health of the environment is the health of themselves because the environment in which they live affects their entire life.

Generally, the Gedeo people protect the environment for different reasons. The environment has economic value because it serves as sources of food, medicine, ritual objects and so on. Thus, in terms of ethics, we can say that the preservation of the environment is vital to the Gedeo for almost a number of utilitarian reasons.

Besides, the Gedeo also protect the environment for nonutilitarian values as well. Animals and plants are the providers of recreational enjoyments and aesthetic pleasure. Plants and animals play a key role in ecological balance (stabilizing the environment). Moreover, trees are believed to have spiritual value because it has association with Megeno. The sage informants believe that some trees are considered as sacredbecause of the location, function and size of the trees. For example, a tree which is found around religious institutions (like, church) where worship is conducted is considered as sacred tree. Therefore, the indigenous environmental ethics of the Gedeo people is more or less having a feature of the ethics of Holmes Roleston (2003) called 'a holistic ethics. The 'holistic ethics' encompasses both intrinsic and instrumental values. It believes that the environment has multiple values. Moreover, it is also associated with "The Preservation Ethics" of John Muir (1916) which advocated preserving undamaged nature, for its own sake and for human fulfillment. And "Shallow Ecology" of Arne Neass (1973) which holds that humans have a responsibility to protect the environment so it can support human life both in the present and in the future..

\section{Conclusion}

Despite the divergent meanings given by informants, the meaning of indigenous environmental ethics for the Gedeo people, undoubtedly, is understandable. The informants believe that environmental ethics for the Gedeo people is the moral duty of man towards the 'environment'. The mystery of divergent connotation about environmental ethics is the term 'environment' itself. For some informants environment is merely plants and animals. For others it is to mean the 'biosphere entities'. Others also believe 'the ecosphere'. Still others also believe that environmental ethics requires the intervention of super- natural power, Megeno (God). However, many informants believe that environmental ethics is the moral duties of man towards plants, animals, land features and other elements of the environment which is so essential for the stable existence of the present and future generation. Therefore, the scope of environmental ethics embraces the intervention of Megeno in the moral relation of man with environment.

Environmental ethics for the Gedeo people have both utilitarian and non-utilitarian values, and intrinsic and extrinsic values. From utilitarian perspective the environment is the source of economic value such as source of food, materials for construction, medicine, firewood, and so on. Conversely, from non-utilitarian perspective the environment is the source of aesthetical and spiritual values. They recognize some plants Adbar (as sacred trees) and place of celebration, worshiping, blessing, peace and negotiation.

Besides, there are different factors that guide the moral relation between the Gedeo people with their environment. Religious sentiments, traditional values and practices, social institutions (like, Songo) compel the community to revere the environment. The environment is given for man by God in the sense of stewardship because man is the only rational being on the earth. Hence, the relationships between man and nature for them, is morally binding, culturally and historically deep rooted. So for the Gedeo people the issue of justice, integrity, and stability is not merely human virtues but they extend them to the environment as well. The Gedeo, thus, believe that the environment and human beings are linked in a net of relationships.

Regarding to the moral obligation of the Gedeo people towards the environment our informants believes that there are various things that serve as a foundation. Morality, religion, culture, history, indigenous knowledge, social 
institutions are the main foundation of obligation. Morally, people believe that destroying the environment is depriving the present and the future generation. Religiously, they also believe that, the Gedeo are one part of nature from the creation of Megeno. This view is connected with the thoughts of Aldo Leopold's (1949) "Land Ethics" which says humans should consider themselves as parts of nature and to attempt to maintain "the integrity, beauty, and stability of the biotic community". Besides, the bible also says (genesis 2) "man is created from the dust and placed in the garden to till and to protect". Historically, the oral tradition of the Gedeo shows human-environment relations and the moral duty of man towards the environment inherited from the father of the Gedeo's called Deraso. Institutionally, the traditional institution of the Gedeo (Songo) teaches the moral obligation of man towards the environment. And culturally, the present generation is responsible to preserve and maintain natural resources in a good manner to the next generation. This view is also supported by "The Conservation Ethics" of Gifford Pinchot which advocates the use of natural resources, but utilizing them wisely to maximize goodness for the greatest number for a long period of time.

Environmental ethics have socio-economic importance for the Gedeo people. Socially, the Gadda system and the Songo have shaped the environmental ethics of the Gedeo people. Trees for the Gedeo are means of boarder conflict resolution, symbol of justice, community gathering sites, and means of sacred activities. And economically, it has a lot of significance too.

Therefore, the indigenous environmental ethics of the Gedeo people is essentially having a feature of the ethics of Holmes Roleston (2003) called 'a holistic ethics' which encompasses both intrinsic and instrumental values. Besides, it is also associated with "The Preservation Ethics" of John Muir (1916) which advocated preserving unspoiled nature, for its own sake and for human needs; and "Shallow Ecology" of Arae Neass (1973) which holds that humans have a responsibility to protect the environment so it can support human life both in the present and in the future.

Generally, the Gedeo people developed both anthropocentric and non-anthropocentric views towards the environment. Because they provide utilitarian and nonutilitarian values, intrinsic and extrinsic values, and the power of domination and stewardship for man towards the environment. Therefore, the indigenous environmental ethics of the Gedeo is holistic in its nature and it is implicit and unwritten. Their indigenous environmental ethics is found in their cultural practices, institutions, histories and practices.

\section{References}

[1] Andrew L. (2003). Anthology of environmental ethics: Blackwell Publishing Company: USA.
[2] Attfield R. (1987). The Ethics of power. African philosophical inquiry. 1(2). 141-156.

[3] C. R. Kothari (2004). Research methodology: methods and techniques. New Age International: New Delhi.

[4] Donland Van DeVeer and Christine Pierce. (1994). The environmental ethics and policy book: Philosophy, ecology, Economics. Wadsworth Publishing Company. North Carolina State University, USA.

[5] J. Baird Callicott (1987). Companion to a sand county almanac: University of Wisconsin Press. Madison.

[6] Kelbessa W. (2011). Indigenous and modern environmental ethics: a study of the indigenous Oromo environmental ethic and modern issuesof environment and development. Cultural heritage and contemporary change Series II. Africa. 13, pp. 1235 .

[7] The Holy Bible (1957). Standard version (revised): London, Thomas Nelson and Sons LTD.

[8] Tom H. (1994). Comparative environmental ethics: University of California Press. California.

[9] Leopold A. (1949). A sand county almanac: Oxford, Oxford University Press.

[10] Lynn White (1967). The historical roots of our ecologic crisis: American association for the advancement of Science. 155. No. 3767, pp. 1203-1207.

[11] Marshall C. (1989). Designing qualitative research: Newbury Park, CA: Sage.

[12] Muir J. (1916). A Thousand mile walk to the gulf: Boston: Houghton Mifflin.

[13] Naess A. (1973). The shallow and the deep long-range ecology movement: A summary inquiry. 16, pp. 95-100.

[14] Ojomo P. (2011). Environmental ethics: An African understanding. African journal of environmental science and technology. 5(8), pp. 572-578.

[15] Passmore J. (1974). Man's responsibility for nature: Ecological problems and western traditions. London: Duckworth.

[16] Paul Sillitoe (1998). The development of indigenous knowledge: $A$ new applied anthropology. Current Anthropology: 39, no. 2, pp. 223-52.

[17] Richard G. Botzler and Susan J. Armstrong (1998). Environmental ethics: Divergence and convergence: Mc Graw Hill, Boston.

[18] Shrader-Frechette, Kristin (2002). Environmental justice: Creating equality. reclaiming democracy: New York, Oxford University Press.

[19] Singer P. (1986). Animal liberation: A new ethics for our treatment of animals: London, Jonathan Cape. Stone, C. (1974) Should Trees Have Standing: Toward Legal Rights for NaturalObjects: Wadsworth Publishing Company. 